\title{
A short peptide derived from pigment epithelial-derived factor exhibits an angioinhibitory effect
}

\author{
Tsung-Chuan Ho', Shu-I Yeh" ${ }^{2,3}$, Show-Li Chen ${ }^{4}$, Ting-Wen Chu ${ }^{3}$ and Yeou-Ping Tsao ${ }^{1,2,3^{*}}$
}

\begin{abstract}
Background: Pigment epithelial-derived factor (PEDF), a $50 \mathrm{kDa}$ secreted glycoprotein, exhibits distinct effects on a range of cell types. PEDF has been shown to inhibit vascular endothelial growth factor (VEGF)-mediated angiogenesis and widely accepted as a promising agent for treatment eye diseases related to neovascularization. A pool of short peptide fragments derived from PEDF reportedly manifests angioinhibitory activity. This study aims to determine the minimal PEDF fragment which can exert the anti-VEGF effect.
\end{abstract}

Methods: A series of shorter synthetic peptides, derived from the 34-mer (PEDF amino acid positions Asp44-Asn77), were synthesized. An MTT assay was used to evaluate the ability of the 34-mer-derived peptides to inhibit VEGFinduced proliferation of multiple myeloma RPMI8226 cells. Cell apoptosis was monitored by annexin V-FITC staining. Western blot analysis was used to detect phosphorylated kinases, including c-Jun N-terminal kinase (JNK) and p38 mitogen-activated protein kinase (MAPK), and the expression of apoptosis-associated proteins, including p53, bax and caspase-3. VEGF-mediated angiogenesis of human umbilical vein endothelial cells (HUVECs), rat aortic ring and mouse cornea were used to detect the angioinhibitory activity of the PEDF-derived peptides.

Results: The MTT assay showed that the anti-VEGF effect of a 7-mer (Asp64-Ser70) was 1.5-fold greater than the 34-mer. In addition, massive apoptosis (37\%) was induced by 7-mer treatment. The 7-mer induced JNK phosphorylation in RPMI8226 cells. Cell apoptosis and apoptosis-associated proteins induced by the 7-mer were blocked by pharmacological inhibition of JNK, but not p38 MAPK. Moreover, the 7-mer prevented VEGF-mediated angiogenesis of endothelial cells (ECs), including tube formation, aortic EC spreading and corneal neovascularization in mice.

Conclusions: This is the first study to show that the PEDF 7-mer peptide manifests anti-VEGF activity, further establishing its potential as an anti-angiogenic agent.

Keywords: Pigment epithelial-derived factor, Vascular endothelial growth factor, Peptide, Corneal neovascularization, Apoptosis

\section{Background}

Pigment epithelial-derived factor (PEDF) was initially identified in the culture supernatant of human fetal retinal pigment epithelial cells, with the ability to promote

\footnotetext{
*Correspondence: yptsao@yahoo.com

${ }^{2}$ Department of Medicine, Mackay Medical College, Zhongzheng Rd., Sanzhi Dist, New Taipei City 25245, Taiwan

Full list of author information is available at the end of the article
}

neuronal differentiation of retinoblastoma Y79 cells [1]. Further studies showed PEDF to be a potent angiogenic inhibitor and the pathological neovascularization in retina is associated with low levels of PEDF in the ocular vitreous humor $[2,3]$. Presently, full-length PEDF is considered to be less suitable as an anti-angiogenic agent than PEDF-derived active fragments because of several issues, including antigenicity, stability, production cost and, perhaps, its multifunctional nature $[4,5]$. In 
this regard, the 34-mer and a shorter peptide within the 34-mer (an 18-mer, Asn60-Asn77) were investigated for the anti-angiogenic activity of PEDF, including induction of endothelial cell apoptosis, blockage of VEGF-induced neovessel formation, analyzed by a mouse corneal pocket assay, and reduction of vascular density in tumor tissues $[4,6]$. In addition, the 34-mer and 18-mer have been shown to have no neurotrophic activity, suggesting that they posses only PEDF anti-angiogenic function $[4,6,7]$.

VEGF is an important proangiogenic factor responsible for the development and formation of blood vessels. VEGF binds to the tyrosine kinase receptors of vascular endothelial cells to induce cell proliferation, migration and sprouting angiogenesis [8]. In addition, VEGF is important for maintenance of the integrity of pericyteendothelial interactions in the retinal microvasculature [9]. VEGF is strongly involved in several angiogenesisdriven eye diseases. For example, anti-VEGF drugs, including pegaptanib (Macugen) and ranibizumab (Lucentis), have been approved for treating retinal and choroidal vascular diseases, such as diabetic macular edema and exudative age-related macular degeneration (AMD). Notably, it has been found that many exudative AMD patients have a persistent hemorrhage and progressive fibrosis at the retinal fovea, following long-term treatment with current anti-VEGF drugs, rendering significant unmet medical needs [10]. VEGF also has a particular angiogenesis-independent effect. For example, VEGF can promote proliferation of multiple myeloma cells in culture [11, 12].

Development of PEDF-based angioinhibitory therapies may be helpful for resolving the problem of persistent side effects associated with current anti-VEGF drugs. In this study, a series of shorter peptides covering the 34-mer were synthesized. We investigated their antiVEGF activity using an established model of multiple myeloma RPMI8226 cell growth induced by VEGF. The 7-mer had effective anti-VEGF activity. Moreover, we demonstrated for the first time that the 7-mer was able to abolish VEGF-induced angiogenesis in vitro and in a mouse model of corneal neovascularization.

\section{Methods}

\section{Materials}

VEGF and TACS annexin V-FITC kits were purchased from R\&D Systems (Minneapolis, MN, USA). Matrigel was purchased from BD Biosciences (New Bedford, MA, USA). HUVECs were purchased from Cascade Biologics, Inc. (Portland, OR, USA). Hydron (529265), sucrose octasulfate-aluminum complex (S0652) were from Sigma-Aldrich (St. Louis, MO, USA). Culture medium, low-serum growth supplement (LSGS) and fetal bovine serum (FBS) were from Gibco-BRL. 3-(4,5-cimethylthiazol-2-yl)-2,5-diphenyl tetrazolium bromide (MTT) was from Merck (Catalog number 1.11714.0001). SB203580 (p38 MAPK inhibitor) and SP600125 (JNK inhibitor) were purchased from SelleckChem (Houston, TX, USA). All peptides shown in Fig. 1a were synthesized by GenScript (Piscataway, NJ, USA), each peptide being modified by acetylation at the $\mathrm{NH}_{2}$ terminus and amidation at the $\mathrm{COOH}$ terminus to improve its stability, with subsequent characterization by mass spectrometry (>95\% purity). Peptides were reconstituted in DMSO as stock $(10 \mathrm{mM})$.

\section{Culture of RPMI8226 cells and MTT assay}

Human multiple myeloma cells, RPMI8226 were purchased from Bioresource Collection and Research Center (Hsinchu, Taiwan). Cells were cultivated in RPMI1640 medium supplemented with $10 \% \mathrm{FBS}, 50 \mu \mathrm{g} / \mathrm{ml}$ penicillin, $50 \mu \mathrm{g} / \mathrm{ml}$ streptomycin, and $2 \mathrm{mML}$-glutamine at $37^{\circ} \mathrm{C}$ in a $5 \% \mathrm{CO}_{2}$ atmosphere. Cell viability was determined by an MTT assay. Cells were cultured in serumfree medium for $24 \mathrm{~h}$, and then seeded in 48 -well culture plates $\left(3 \times 10^{5}\right.$ cells/well $)$ and cultured in $0.5 \mathrm{ml}$ fresh serum-free RPMI1640 medium supplemented with $10 \mathrm{ng} / \mathrm{ml}$ VEGF and $20 \mu \mathrm{M}$ PEDF peptide for a further $24 \mathrm{~h}$. Subsequently, $50 \mu \mathrm{l}$ of the MTT stock solution $(5 \mathrm{mg}$ MTT dissolved in $1 \mathrm{ml}$ of sterile PBS) was added each well, and incubated at $37^{\circ} \mathrm{C}$ for $4 \mathrm{~h}$. MTT stock solution added to medium alone was included as a negative control. Aliquots $(450 \mu \mathrm{l})$ from each sample were transferred to a new well of a 48 -well culture plate, $100 \mu$ l DMSO added with thorough mixing, and allowed to react at $37^{\circ} \mathrm{C}$ for $20 \mathrm{~min}$ before reading the absorbance at $570 \mathrm{~nm}$.

\section{Cell culture of HUVECs}

Cells were grown in Medium 200 with LSGS (supplement contains $1.9 \%$ fetal bovine serum, $3 \mathrm{ng} / \mathrm{ml}$ bFGF, $10 \mu \mathrm{g} /$ $\mathrm{ml}$ heparin, $1 \mu \mathrm{g} / \mathrm{ml}$ hydrocortisone, and $10 \mathrm{ng} / \mathrm{ml} \mathrm{EGF).}$ Culture plates were coated with $2 \%$ gelatin. Cells (passages $4-8$ ) were cultured at $37^{\circ} \mathrm{C}$ in a humidified atmosphere of $5 \% \mathrm{CO} 2$. For peptide treatment, HUVECs were cultured in low serum (0.5\% FBS) medium containing $20 \mathrm{ng} / \mathrm{ml}$ VEGF and 7-mer peptide $(20 \mu \mathrm{M}$, unless otherwise specified).

\section{Endothelial cell capillary-like tube formation assay}

Growth factor-reduced matrigel was pipetted into prechilled 24-well plates $(150 \mu \mathrm{l}$ matrigel per well $)$ and polymerized for $45 \mathrm{~min}$ at $37^{\circ} \mathrm{C}$. HUVECs $\left(4 \times 10^{4}\right.$ per well) in low serum $(0.5 \%$ FBS $)$ medium were treated with $20 \mathrm{ng} / \mathrm{ml}$ VEGF and 7 -mer $(10 \mu \mathrm{M})$ in matrigel coated plates. After $6 \mathrm{~h}$ of incubation, tubular structures were photographed. Images were captured using 


\section{a}

\begin{tabular}{|cc|}
\hline 34-mer -- DPFFKVPVNK LAAAVSNFGY DLYRVRSSTS PTTN \\
18-mer -- & NFGY DLYRVRSSTS PTTN \\
14-mer -- & DLYRVRSSTS PTTN \\
10-mer -- & DLYRVRSSTS \\
7-mer -- & DLYRVRS \\
$6-\mathrm{mer}--$ & DLYRVR \\
5-mer -- & DLYRV
\end{tabular}

b
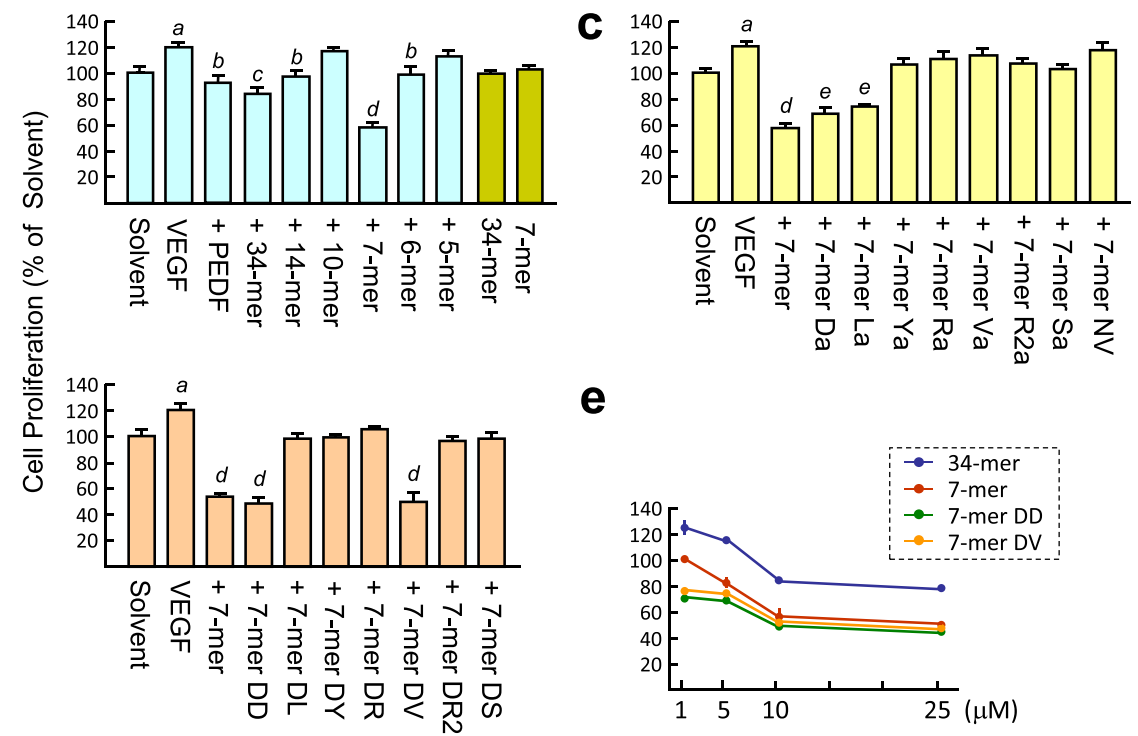

e

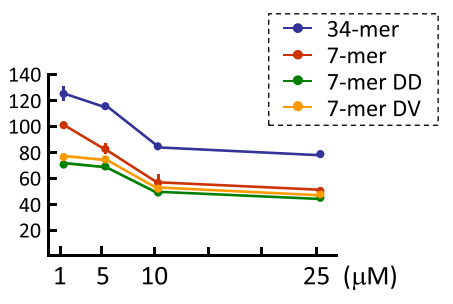

Fig. 1 Analysis of the effect of 34-mer derived peptides on the VEGF-induced RPMI8226 cell proliferation. a Sequence diagram of the peptides derived from the 34-mer. b-e VEGF-induced cell proliferation was measured by an MTT assay. Cells were treated with $10 \mathrm{ng} / \mathrm{ml} \mathrm{VEGF} \mathrm{in} \mathrm{the} \mathrm{presence}$ of $25 \mu \mathrm{M}$ peptide for $24 \mathrm{~h}$. The MTT value of peptide solvent-treated RPMI8226 cells was set at $100 \%$. Results represent the mean \pm SD from three independent experiments. ${ }^{a} P<0.05$ versus solvent. ${ }^{b} P<0.001,{ }^{c} P<0.0001,{ }^{d} P<0.00002$ and ${ }^{e} P<0.00004$ versus VEGF treatment

a Cannon camera on a Zeiss inverted microscope with magnification $\times 40$.

\section{Western blot analysis}

Cell lysis and SDS-PAGE were as described previously [13]. Antibodies used in this study were for active p38 MAPK and active JNK (Promega, Madison, WI), p38 MAPK/SAPK2, JNK (Upstate Biotechnology, Lake Placid, NY), p53 (Chemicon, Temecula, CA), bax, p21, cleaved caspase- 3 and $\beta$-actin (Abcam Ltd., Cambridge, UK). Proteins of interest were detected using the appropriate IgG-horseradish peroxidase-linked secondary antibody (Santa Cruz Biotechnology) and enhanced chemiluminescence reagent (Amersham, Arlington Heights, IL). X-ray films were scanned on a model GS-700 Imaging Densitometer (Bio-Rad, Hercules, CA) and analyzed with Labworks 4.0 software. For quantification, blots from at least three independent experiments were used.

\section{Annexin-V/propidium iodide ( $\mathrm{PI})$ double-staining assay} Cell apoptosis was examined using a TACS annexin V-FITC kit according to the manufacturer's instructions for in situ staining. The cell numbers were monitored by counterstaining with Hoechst 33342. Afterward, apoptosis was examined and photographed by a Zeiss epifluorescence microscope $(\times 100,10$ fields/sample). Images were recorded on Zeiss software.

\section{Animal studies}

All animals were housed in an animal room under temperature control $\left(24-25^{\circ} \mathrm{C}\right)$ and a 12:12 light-dark cycle. Standard laboratory chow and tap water were available ad libitum. Experimental procedures were approved by the Mackay Memorial Hospital Review Board (project code: MMH-A-S-103-10; New Taipei City, Taiwan). Animals in ophthalmic research were performed in compliance with national animal welfare regulations (Council of Agriculture, Taiwan, ROC), the ARVO Statement and the ARRIVE Guidelines. C57BL/6 mice with an age of 
6 weeks were anaesthetized by an intraperitoneal injection of a mixture of ketamine ( $100 \mathrm{mg} / \mathrm{kg}$ body weight) and xylazine $(10 \mathrm{mg} / \mathrm{kg})$. All animals were euthanized by $\mathrm{CO}_{2}$ inhalation prior to dissection.

\section{Rat aortic ring assay}

Thoracic aortas were removed from euthanized 10-weekold male Sprague Dawley rats and gently stripped of periaortic fibroadipose tissue. Aortas were sectioned into $\sim 1 \mathrm{~mm}$ length rings, being manipulated in Medium 200. Matrigel $(120 \mu \mathrm{l})$ mixed with $24 \mu \mathrm{l}$ LSGS, $72 \mu \mathrm{l}$ medium, $200 \mathrm{ng} / \mathrm{ml}$ VEGF and $100 \mu \mathrm{M} 7$-mer was used to embed the aortic ring and then polymerized in 12-well plates $\left(37^{\circ} \mathrm{C}\right.$ for $\left.30 \mathrm{~min}\right)$. Subsequently, $1 \mathrm{ml}$ culture medium supplemented with 100 units/ml penicillin, and $100 \mathrm{ng} /$ $\mathrm{ml}$ streptomycin was added. The cultures were propagated at $37^{\circ} \mathrm{C}$ in a humidified incubator for up to 5 days. Sprouts were recorded using an inverted microscope platform (Leica DMI6000B) with bright-field optics. Each ring was scored by three independent observers on a scale $0-3$, depending on the degree of vessel sprouting observed $(0=$ no sprouting, $3=$ profuse sprouting).

\section{Mouse corneal micropocket assay}

The assay was performed according to procedures described previously [14]. Briefly, corneal micropockets were created in 6-week-old C57BL/6 mice with the needle of $1-\mathrm{ml}$ injector. A micropellet of sucrose aluminum sulfate and hydron polymer containing $200 \mathrm{ng}$ VEGF, with or without $2.5 \mu \mathrm{g} 7$-mer peptide, was delivered into each corneal pocket. Eyes were photographed by a slit-lamp biomicroscope on day 7 after micropellet implantation. Ingrowth of the blood vessels into the avascular cornea, towards the pellet, was scored as a positive response. The results are reported as the fraction of positive corneas of the total implanted.

\section{Statistics}

The data were generated from at least three independent experiments. All numerical values are expressed as the mean $\pm S D$. Comparisons of two groups were made using the Mann-Whitney test. $P<0.05$ was considered significant.

\section{Results}

Identification of an active core region in the PEDF 34-mer, in terms of its anti-VEGF activity

We used an MTT assay to measure the growth and survival of multiple myeloma RPMI8226 cells induced by VEGF. PEDF blocked the VEGF effect $(93 \pm 3.8 \%$ versus $120 \pm 3.9 \%$; untreated cells set as $100 \%$; Fig. 1b), similar to previous reports $[11,15]$ and the 34-mer displayed a stronger inhibitory effect than PEDF $(84 \pm 4.0 \%)$. The 14-mer, missing the 20 amino acids at the $\mathrm{N}$-terminal end of the 34-mer, had a weaker anti-VEGF effect $(97 \pm 3.6 \%)$. We deleted the amino acid residues at the $\mathrm{C}$-terminal end of the 14-mer to generate a 10 -mer, 7-mer, 6-mer, and 5 -mer and these yielded values of $116 \pm 2.64 \%, 58 \pm 4.1 \%$, $99 \pm 6.2 \%$ and $113 \pm 4.2 \%$, respectively, in the MTT assay. The 10-mer and 5-mer failed to suppress the VEGF effect, but the 6-mer had the same anti-VEGF activity as the 14-mer. Unexpectedly, the 7-mer exhibited more potent anti-VEGF activity than the 34-mer $(\sim 1.5$-fold). Notably, treatment of RPMI8226 cells with the 34-mer and 7-mer in the absence of VEGF showed that neither peptide had a significant cytotoxic effect. This result supports the previous finding that the anti-angiogenic activities of PEDF and the 34-mer are involved in selectively inducing apoptosis of proliferating ECs, rather than quiescent ECs [16]. In addition, as depicted in Fig. 1c, single alanine substitutions of the Y66, R67, V68, R69 and $\mathrm{S} 70$ residues of the 7 -mer, cause a large drop in the anti-VEGF activity of the 7-mer $(97.1 \% \sim 106.9 \%$ versus 57.3\%), whereas substitutions of the D64 and L65 residues cause a modest decrease in anti-VEGF activity $(69 \pm 3.5 \%$ and $74 \pm 0.9 \%)$. We prepared the D64N/L65V double mutant of the 7-mer to determine whether this peptide retained anti-VEGF activity. However, the D64N/ L65V double mutation was deleterious to the anti-VEGF activity of the 7 -mer $(117 \pm 4.1 \%)$. Collectively, truncation of the 34-mer peptide identifies the 7-mer as a core active region of the 34-mer, in terms of its anti-VEGF effect on RPMI8226 cells. The results also reveal that the anti-VEGF activities of 34-mer-derived peptides are varied and associated somewhat with amino acid residues near the $\mathrm{N}$ - and $\mathrm{C}$-termini of the 7 -mer region.

\section{The D-form 7-mer peptide exerts higher anti-VEGF effect in vitro than its L-form isomer}

Natural L-amino acids are unstable in vivo because they are susceptible to protease degradation. To improve the resistance of the 7-mer to proteolysis, D-amino acid substitution was used for peptide modification. Using D-amino acids for peptide modification have been suggested potentially to promote the peptide therapeutic activity [17]. To investigate whether 7 -mer modified by D-amino acids can enhance its anti-VEGF activity in the RPMI8226 cells, an MTT assay revealed that replacement of the D64 and V68 residues of the 7-mer by D-amino acids (7-mer DD and 7-mer DV) retained anti-VEGF activity comparable to the 7 -mer $(49 \pm 4.3 \%$ and $49 \pm 7.0 \%, 54 \pm 1.5 \%)$. whereas On the other hand, $\mathrm{D}$-amino acid substitution of the other residues of the 7-mer yielded peptides with much less activity against the VEGF effect on RPMI8226 cells ( 105-98\%) at the tested concentration $(25 \mu \mathrm{M}$; Fig. 1d). Next, the VEGF-treated 


\section{a}
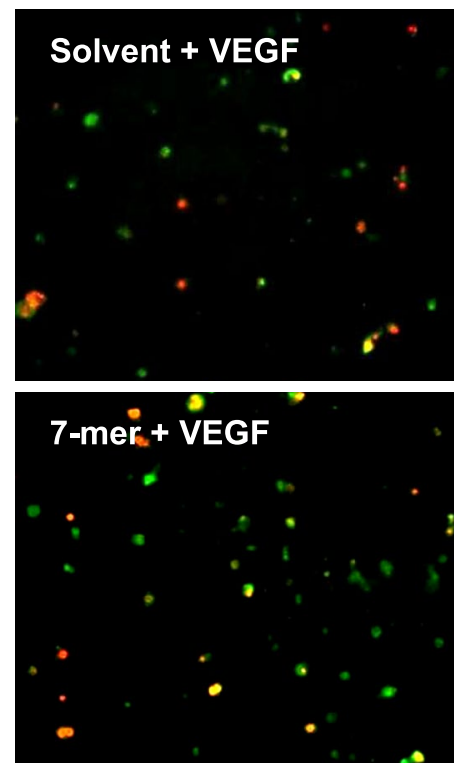
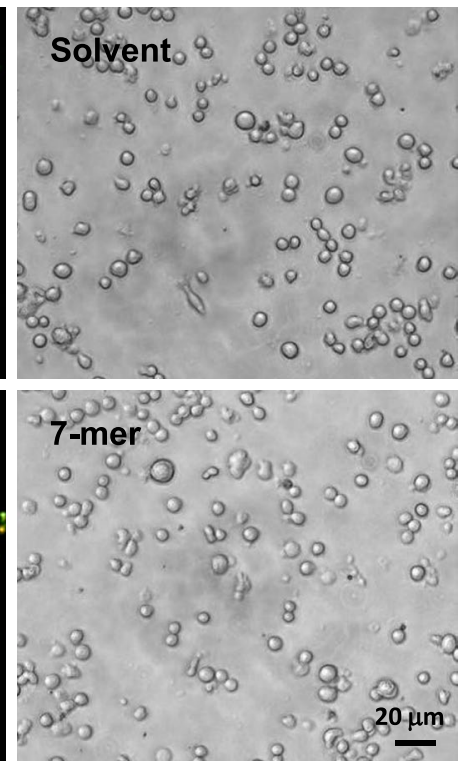

b

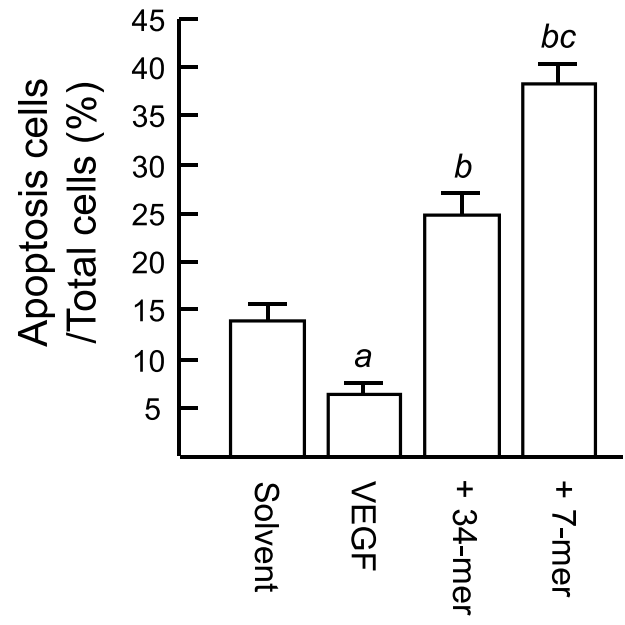

Fig. 2 The 34-mer and 7-mer induce apoptosis of RPMI8226 cells. a Fluorescence microscopy of annexin V-FITC/PI double staining. Treatment of RPMI8226 cells was as described in Fig. 1. Apoptosis was determined by annexin V-FITC staining (green dots) and double stained with propidium iodide (red dots). A representative of three independent experiments is shown. $\mathbf{b}$ The percentage of apoptotic cells was quantified by dividing the number of annexin $V$-positive cells by the total number of cells counted by phase-contrast light microscopy. Control peptide indicates cells were treated with the 5 -mer. Histograms show means \pm SD. ${ }^{a} p<0.005$ versus peptide solvent-treated cells. ${ }^{b} p<0.0002$ versus VEGF-treated cells. ${ }^{c} P<0.001$ versus 34-mer-treated cells

RPMI8226 cells were exposed to various doses of the 7 -mer peptide $(1,5,10$ and $25 \mu \mathrm{M})$. An MTT assay showed that treatment with the 7-mer, 7-mer DD and 7-mer DV decreased cell viability in a dose-dependent manner (Fig. 1e). We noted that the 7-mer DD and 7-mer DV had a greater anti-VEGF effect than the 7 -mer at the lowest concentration $(1 \mu \mathrm{M} ; 75 \pm 2.8 \%$ and $78 \pm 1.7 \%$ versus $101 \pm 1.2 \%)$. In contrast, cell viability decreased significantly with the 34 -mer treatment at 10 and $25 \mu \mathrm{M}$, but not at 1 and $5 \mu \mathrm{M}$. Taken together, these results indicate that the D-form 7-mer peptide has a greater anti-VEGF activity than its L-form.

\section{The 34-mer and 7-mer induce RPMI8226 cell apoptosis}

We next investigated whether the 34-mer and 7-mer can induce apoptosis of VEGF-treated RPMI8226 cells by annexin V-FITC/PI double staining. This technique has been used to detect viable cells (annexin $\mathrm{V}^{-} / \mathrm{PI}^{-}$), cells undergoing early apoptosis (annexin $\mathrm{V}^{+} / \mathrm{PI}^{-}$), late apoptotic cells (annexin $\mathrm{V}^{+} / \mathrm{PI}^{+}$) and necrotic cells (annexin $\mathrm{V}^{-} / \mathrm{PI}^{+}$; Fig. 2a). The simultaneous detection of early and late apoptosis (annexin $\mathrm{V}^{+}$cells) revealed that withdrawal of serum from the culture medium caused apoptosis of RPMI82226 cells, whereas VEGF could prevent this serum deprivation-induced apoptosis (annexin $\mathrm{V}^{+}$cells:
$14.0 \pm 1.7 \%$ versus $6.5 \pm 1.1 \%$; Fig. $2 \mathrm{~b})$. Importantly, there was a significant increase of cell apoptosis after treatment with the 34-mer and 7-mer for $24 \mathrm{~h}(25.1 \pm 2.2 \%$ and $38.6 \pm 2.1 \%$, respectively). In addition, Necrosis (annexin $\mathrm{V}^{-} / \mathrm{PI}^{+}$) was rare after cells received these treatments. In addition, we noted that part of apoptotic RPMI8226 cells displayed morphologic changes, including shrinkage and membrane blebbing, resulting in different sizes of green dots. A previous report also indicates that PPAR $\gamma$ overexpression in RPMI8226 cells induces cells undergoing apoptosis with morphologic hallmarks, such as shrinkage and membrane blebbing [18]. Taken together, these findings provide evidence that the 34-mer and 7-mer are able to suppress the VEGF-mediated cell protective effect by inducing cell apoptosis.

\section{The 7-mer triggers JNK-dependent apoptotic signaling in VEGF-treated RPMI8226 cells}

To investigate whether the 7-mer affects JNK and p38 MAPK signaling in RPMI82226 cells, western blot analysis was performed using antibodies against the active phosphorylated forms of JNK and p38 MAPK. An increase in p-p46 JNK was detected $20 \mathrm{~min}$ after 7 -mer treatment, reaching a peak value at $2 \mathrm{~h}$, and the phosphorylation was sustained for up to $10 \mathrm{~h}$. Treatment with the 
7-mer had no significant effect on p38 MAPK phosphorylation (Fig. $3 \mathrm{a}$ and $\mathrm{b}$ ). In this regard, pretreatment of RPMI82226 cells with a JNK inhibitor (10 $\mu$ M SP600125), but not in cells pretreated with a p38 MAPK inhibitor (10 $\mu \mathrm{M}$ SB203580), altered 7-mer-induced RPMI8226 cell apoptosis from $38.6 \pm 2.1 \%$ to $11.6 \pm 1.5 \%$, assayed by annexin V-FITC staining (Fig. 3c).

Overexpression and activation of p53 play a critical role in PEDF-induced endothelial cell apoptosis [19]. As shown in Fig. 4a, western blot analysis showed that treatment with the 7-mer for $8 \mathrm{~h}$ caused an increase of the protein levels of p53 and its transcriptional target genes, including Bax (an apoptosis inducer) and $p 21^{\text {Waf1 }}$ (a cyclin-dependent kinase inhibitor) compared to solvent control $(3.6 \pm 0.39,4.5 \pm 0.40$ and $5.5 \pm 0.43$-fold; Fig. $4 \mathrm{~b})$. Moreover, an increase in p53 expression corresponded to the elevation of cleaved/active caspase-3, a frequently activated death protease in the apoptosis pathway, was observed following 7-mer treatment for $24 \mathrm{~h}$. We determined whether JNK activation induced by the 7-mer can regulate the level of p53 protein. Western blotting revealed that increases in the levels of induced p53, bax, p21, and cleaved caspase-3 were significantly inhibited in cells pretreated with SP600125, but not in cells pretreated with SB203580, suggesting p-JNK engagement in RPMI8226 cell apoptosis or cell cycle arrest induced by the 7-mer. Taken together, our results reveal that apoptosis and the $\mathrm{p} 53 / \mathrm{Bax} / \mathrm{p} 21^{\text {Wafl }}$ pathway induced by the 7-mer were mediated by JNK activation.

\section{The 7-mer exhibits the angioinhibitory activity in HUVECs}

ECs are converted to capillary tube-like structures in response to VEGF. We observed the VEGF effect on HUVECs using a matrigel-based tube formation assay. As depicted in Fig. 5a, exposure of HUVECs to VEGF for $6 \mathrm{~h}$ formed a massive tube-like network as described previously [20] (Fig. 5a). Treatment with the 7-mer and 34-mer resulted in a marked decrease of the VEGF-stimulated tube-like network. Next, we investigated whether the 7-mer can induce apoptosis of HUVECs. The annexin V-FITC staining showed that treatment of HUVECs with the 34-mer and 7-mer for $16 \mathrm{~h}$ increased the percentage of apoptotic cells from $6.3 \pm 1.6 \%$ (VEGF-treated) to $20.1 \pm 4.4 \%$ and $43.0 \pm 5.5 \%$, respectively (Fig. $5 \mathrm{~b}$ ). A control peptide (the 5-mer) had no such effect. These results indicate that the 7-mer has anti-angiogenic activity through arresting VEGF-mediated capillary morphogenesis and inducing endothelial cell apoptosis.

\section{The 7-mer inhibits VEGF-induced microvessel sprouting ex vivo and corneal neovascularization}

The effect of the 7-mer on VEGF-induced microvessel sprouting was evaluated using a rat aortic ring assay.

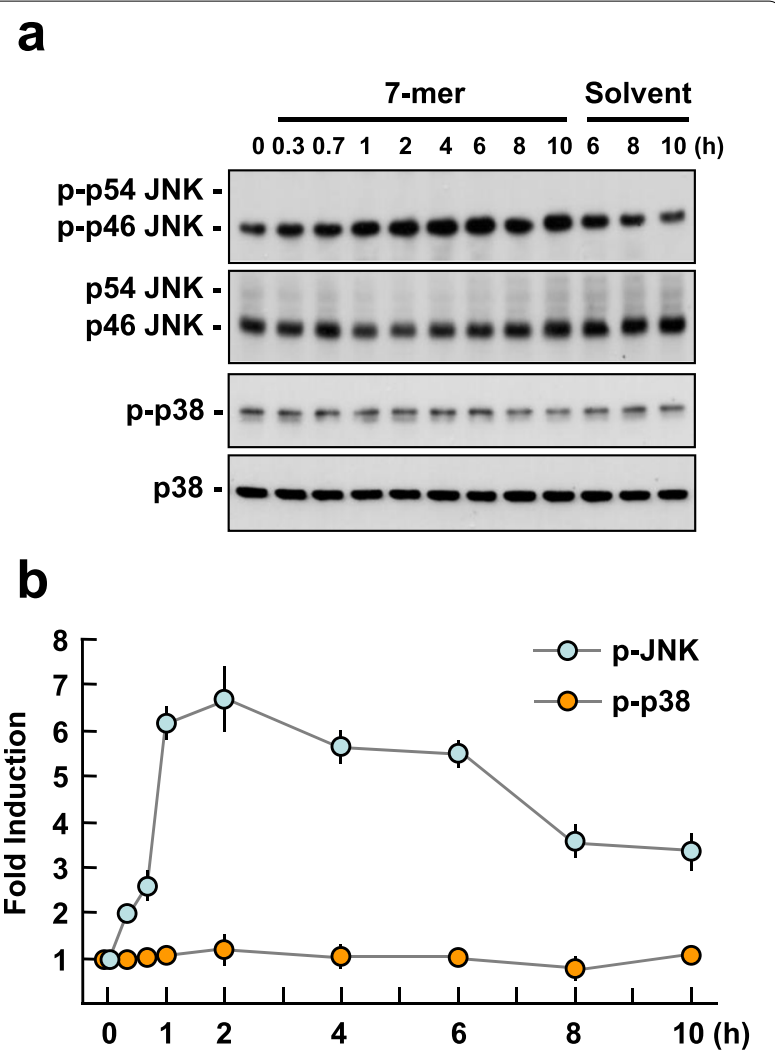

C

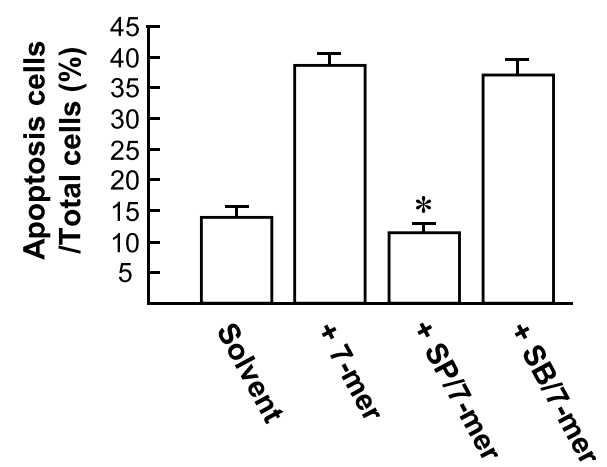

Fig. 3 The 7-mer induces JNK signaling to trigger RPMI8226 cell apoptosis. $3 \times 10^{5}$ cells were serum starved for $24 \mathrm{~h}$ and then exposed to $10 \mathrm{ng} / \mathrm{ml} \mathrm{VEGF}$ and $25 \mu \mathrm{M} 7$-mer for the indicated time periods. a Western blotting was performed to detect the active phosphorylated forms of JNK (p-JNK) and p38 MAPK (p-p38), shown in the upper panels. Antibodies were then stripped and the blots were re-incubated with anti-JNK and anti-p38 MAPK antibodies (lower panels), respectively, to detect the levels of total JNK and p38 MAPK. b Densitometric analyses from three independent experiments are shown. c Cell were pretreated with $10 \mu \mathrm{M}$ SP600125 or SB203580 for $10 \mathrm{~min}$ and then treated as described above for $24 \mathrm{~h}$ and apoptosis was quantified using the annexin V-FITC apoptosis detection kit. ${ }^{*} P<0.0001$ versus 7 -mer-treated cells 
a

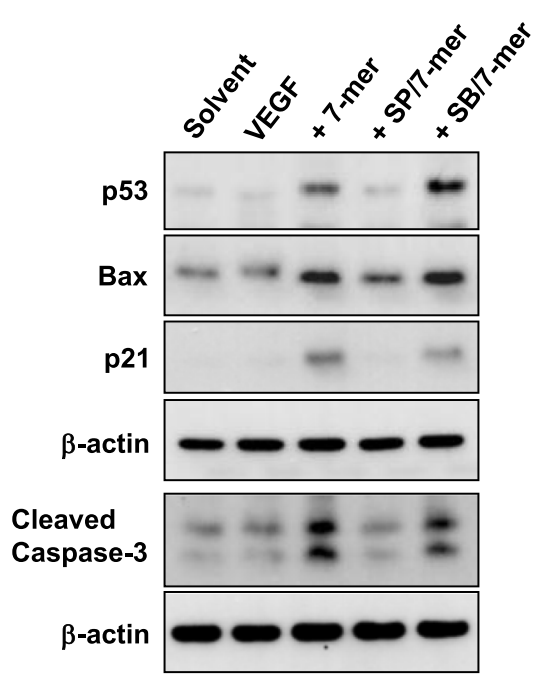

b

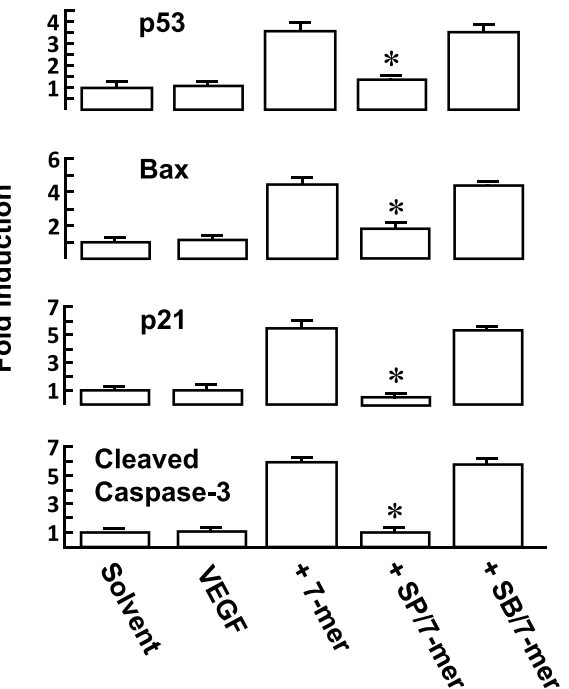

Fig. 4 The 7-mer induces JNK signaling to trigger p53/bax/p21 Waf1 expression in RPMI8226 cells. a and $\mathbf{b}$ Cell treatments were as described in Fig. 3. Cell lysates were then prepared for western blot analysis of p53, Bax, and p21. Representative blots and densitometric analyses from three independent experiments are shown. ${ }^{*} P<0.001$ versus 7 -mer-treated cells

As shown in Fig. 6a, outgrowth of sprouts from the aortic rings was observed after VEGF treatment for 5 days, whereas this outgrowth was suppressed when the VEGF-treated aortic rings were exposed to the 7-mer $(P=0.001)$. In addition, aortic rings exposed to multiple angiogenic factors (LSGS and VEGF) produced profuse sprouts around the ring that were blocked by the 7-mer. Furthermore, in a mouse corneal model of neovascularization, VEGF-induced neovessels in the corneas of C57BL/6 mice were prevented by the 7 -mer (Fig. 6b). The results imply that the 7 -mer is active against angiogenesis in vivo.

\section{Discussion}

Identification of angioinhibitory peptides derived from PEDF may be a promising strategy for improving the treatment of angiogenesis-related diseases. Previous studies have identified the 34-mer (D44-N77) and 18-mer (N60-N77) that preserve the anti-angiogenic and antitumor activities of human PEDF, but the 23-mer (A55-N77) and 14-mer (D64-N77) are devoid of PEDF activity [4]. For example, the 14-mer is unable to induce EC apoptosis in vitro. Here, we found for the first time that the 7-mer peptide (D64-S70), representing a minimal region within PEDF, reproduced the anti-VEGF effect, comparable to the 34-mer. Also, the longer peptides (34-mer, 14-mer and 10-mer) with $\mathrm{N}$ - and C-terminal sequences near the 7-mer region, displayed a rather poor inhibitory effect on VEGF, compared to the 7-mer peptide.

It has been reported that the vitreous humors of exudative AMD patients contain lower levels of PEDF [3]. This reduction of PEDF levels leads to patients' vitreous insufficiency in suppressing EC migration, compared to vitreous humor from age-matched control donors [3]. These findings suggest that loss of PEDF may create a permissive environment for the pathogenesis of exudative AMD. Overexpression of PEDF in mice by intravitreous injection of an adenoviral vector encoding PEDF (AdPEDF) and PEDF transgenic mice have been reported to block laser-induced choroidal neovascularization (CNV) and VEGF-induced retinal neovascularization [21, 22]. This suggests that elevated levels of intraocular PEDF are beneficial in suppressing ocular neovascularization. However, treatment of ocular neovascular diseases with the wild-type (WT)-PEDF may generate additional unexpected effects through its multifunctional activities. These functional effects could come from the interaction of different PEDF domains with an individual receptor on the surface of different types of cells. PEDF is known that contributes to antiangiogenesis, antitumor, antiinflammation, neuroprotection and tissue repair by stem cells [23]. In addition, For example, in comparison with WTPEDF, it has been found that mutation of putative phosphorylation sites in PEDF (phosphomimetic mutants) leads to more profound anti-angiogenic activity and may avoid the induction of tumor growth [24]. In addition, 
a
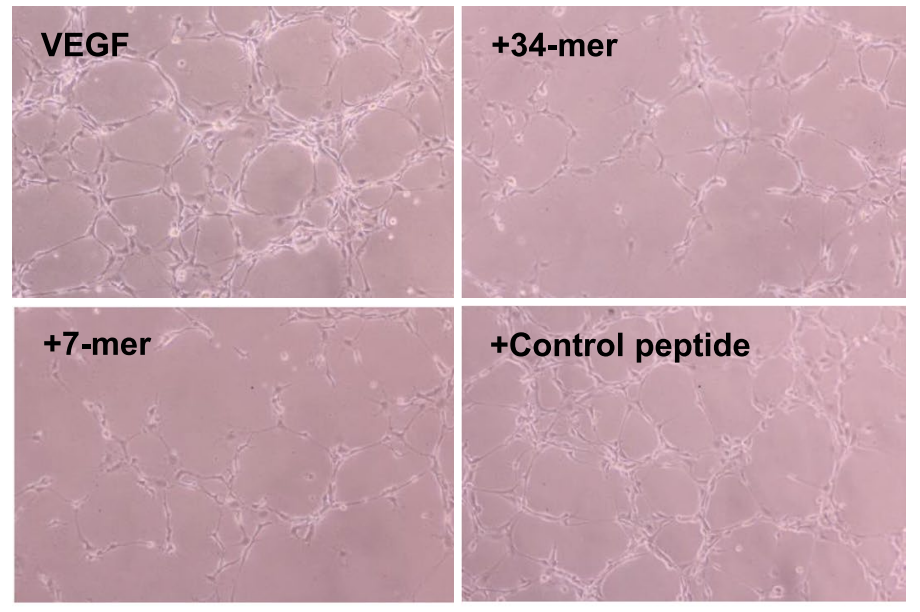

b
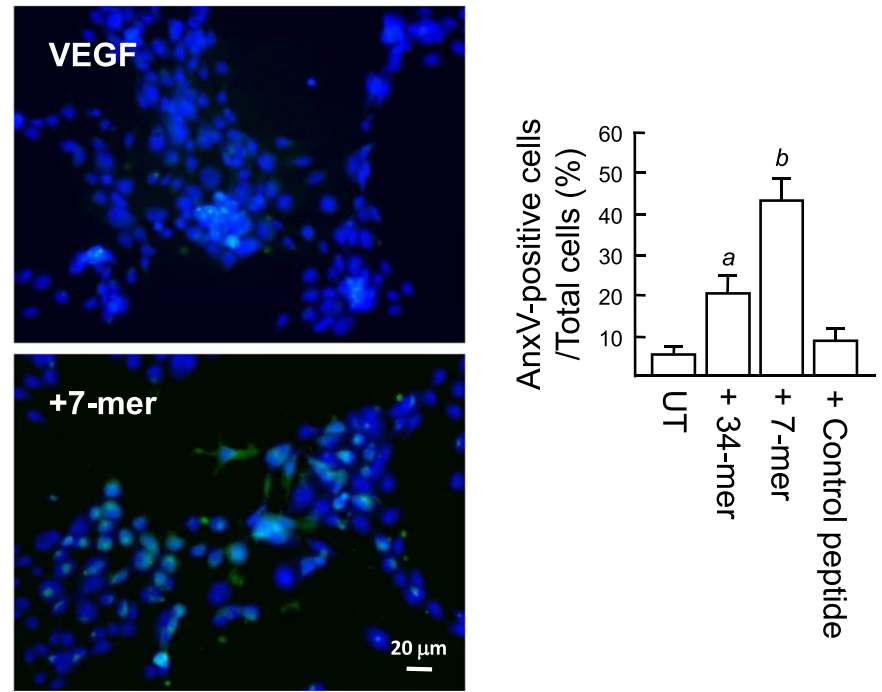

Fig. 5 The 34-mer and 7-mer display angioinhibitory properties in culture. a VEGF-induced capillary-like tubular structures were observed in matrigel with phase-contrast light microscopy. The experiment was repeated three times. Magnification is $\times 40$. b The 7-mer induces HUVEC apoptosis in the presence of VEGF. Cell apoptosis was analyzed using the Annexin V-FITC Apoptosis Detection kit according to the in situ staining protocol after treatment for $16 \mathrm{~h}$. Double staining with an annexin V-FITC and the fluorescent dye Hoechst 33342 was used to visualize the apoptotic cells (green) and nuclei (blue), respectively. A representative result of four independent experiments is shown. The percentages of apoptotic cells were quantified. ${ }^{a} P<0.005$ versus VEGF-treated cells

recombinant PEDF may create complex antigenicity [4]. In this regard, it has been proposed that synthetic antiangiogenic peptides derived from PEDF are more practical as agents for treating neovascularization in tumors and the eye $[4,5]$.

In the present study, the 7-mer induced massive apoptosis of RPMI8226 cells and it is plausible to propose apoptosis as the major anti-VEGF mechanism of the 7-mer in culture, rather than cell cycle arrest alone. In addition, we found that the 7-mer was able to activate JNK signaling in RPMI8226 cells. Pharmacological inhibition of JNK with SP600125 suppressed the 7-mer induced RPMI8226 cell apoptosis. Meanwhile, SP600125 also suppressed the effect of the 7-mer on induction of $\mathrm{p} 53, \mathrm{Bax}, \mathrm{p} 21^{\text {waf1 }}$ and active caspase-3 protein expression. Several studies have shown that the PEDF receptor $(37 / 67 \mathrm{kDa}$ laminin receptor; $\mathrm{LR})$, JNK, PPAR $\gamma$ and p53 and effectors, including FasL and Bax, are associated with PEDF-induced EC apoptosis $[16,17,25,26]$. In particular, it has been demonstrated that a neutralizing antibody against LR can block the effect of PEDF on VEGF-induced multiple myeloma 


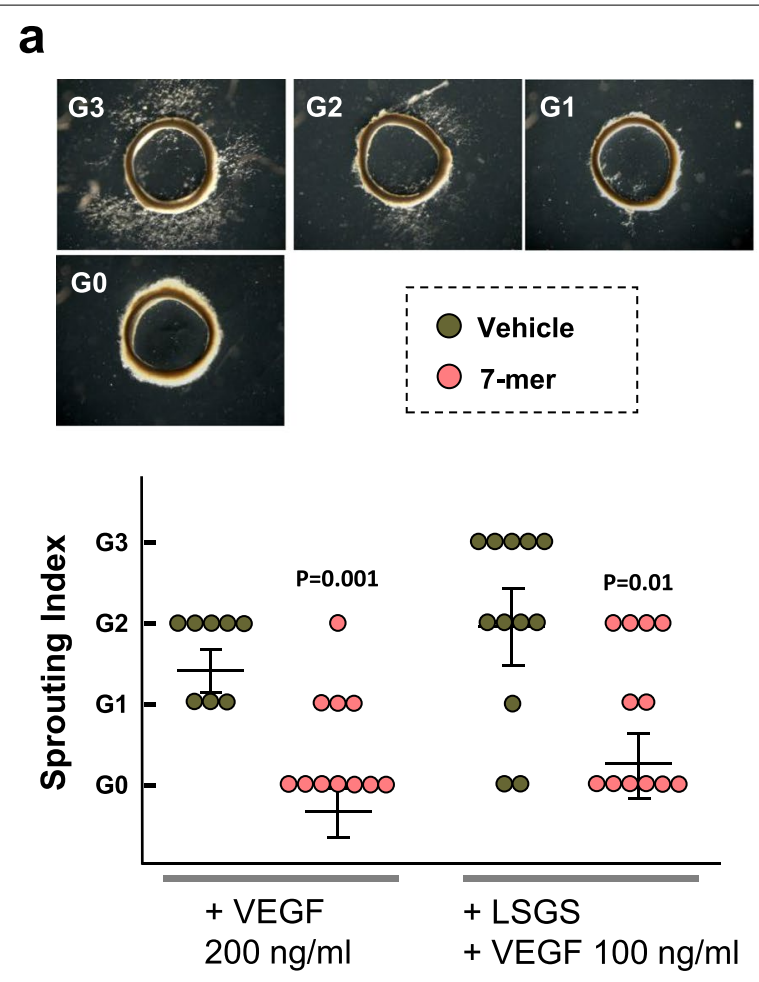

b

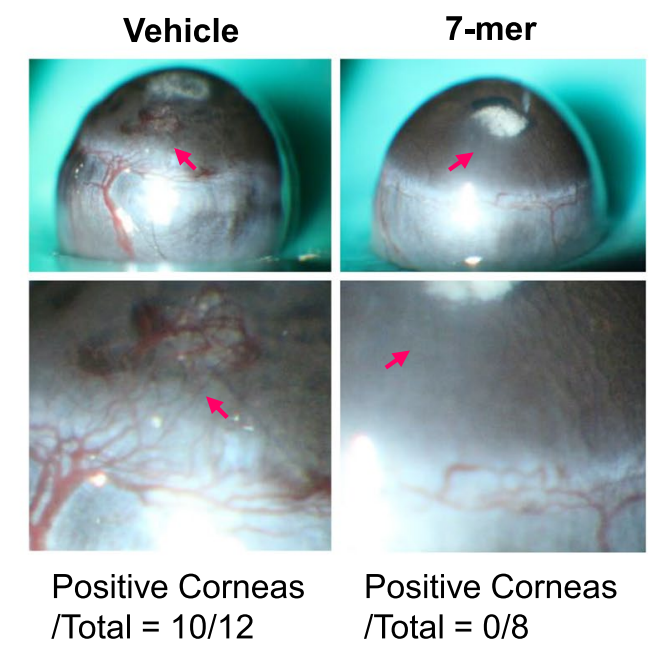

Fig. 6 The effect of the 7-mer on VEGF-induced microvessel sprouting of aortic ring and corneal neovascularization. a Rat aortic ring assay. Photomicrographs of aortic ring explants after treatment for 5 days (magnification $\times 40$ ). Sprouting was evaluated on a scale from 0 (no sprouts) to 3 (profuse sprouting). There was no sprouting of vessels from ex vivo aortic rings embedded in Matrigel without LSGS or VEGF. b The 7-mer inhibits VEGF-induced corneal angiogenesis in C57BL/6 mice. Representative corneas and final scoring determining the number of positive corneas per total implantations. Arrows indicate the corneal region near to the VEGF/ vehicle or VEGF/7-mer pellet cell proliferation [15]. These results suggest that PEDFmediated apoptotic signaling acts on ECs and myeloma cells in a similar manner.

\section{Conclusions}

In summary, identification of PEDF-derived angioinhibitory peptides may facilitate the development of more effective therapeutic strategies for angiogenesis-related eye diseases and potentially with less side effects. VEGFactivated myeloma cells and ECs are responsive to the 7-mer, providing evidence for the 7-mer as an anti-VEGF agent. Further preclinical animal studies of ocular neovascular diseases are required to evaluate the therapeutic efficacy of the 7-mer.

\section{Abbreviations}

PEDF: Pigment epithelial-derived factor; VEGF: Vascular endothelial growth factor; JNK: c-Jun N-terminal kinase; MAPK: Mitogen-activated protein kinase; HUVECs: Human umbilical vein endothelial cells; ECs: Endothelial cells: AMD: Age-related macular degeneration; MTT: 3-(4,5-cimethylthiazol-2-yl)2,5-diphenyl tetrazolium bromide; DMSO: Dimethyl sulfoxide; bFGF: Basic fibroblast growth factor; EGF: Epidermal growth factor; SDS-PAGE: Sodium dodecyl sulfate polyacrylamide gelelectrophoresis; PI: Propidium iodide; CNV: Choroidal neovascularization.

\section{Supplementary Information}

The online version contains supplementary material available at https://doi. org/10.1186/s12886-022-02295-0.

Additional file 1.

\section{Acknowledgements}

We thank Tim J Harrison for kindly reading this manuscript.

\section{Authors' contributions}

YPT and TCH participated in the design of the experiment, analysed the data, and manuscript writing. TCH, SIY and TWC participated in creating the animal model, specimen collection, experimental manipulation, data collection and analysis. SIY and SLC participated in analyzed the results and modified the manuscript. All authors read and approved the final manuscript.

\section{Funding}

This study was supported by grants from the Ministry of Science and Technology, Taiwan (MOST 108-2314-B-195-016-MY3) and Mackay Memorial Hospital (MMH-E-108-006).

\section{Availability of data and materials}

The datasets used and analysed during the current study are available from the corresponding author on reasonable request.

\section{Declarations}

Ethics approval and consent to participate

The Mackay Memorial Hospital Review Board approved the animal study. All animal procedures were conducted in accordance with the ARVO Statement and the ARRIVE Guidelines for the use of animals in ophthalmic research. The animals were purchased from Lasco Co., Ltd. (Taiwan).

Experimental procedures were approved by the Mackay Memorial Hospital Review Board (New Taipei City, Taiwan) and were performed in compliance with national animal welfare regulations (Council of Agriculture, R.O.C). 


\section{Consent for publication}

Not applicable.

\section{Competing interests}

YPT and TCH have competing financial interests. SIY, TWC and SLC have no competing interests as defined by BMC. The findings described in this manuscript have been patented by Mackay Memorial Hospital. The patent has subsequently been licensed to Oculus Biomed Pty Ltd. (OBM), based in Melbourne, Australia.

\section{Author details}

1 Department of Medical Research, Mackay Memorial Hospital, No. 45, Minsheng Rd., Tamsui District, New Taipei City 25160, Taiwan. ${ }^{2}$ Department of Medicine, Mackay Medical College, Zhongzheng Rd., Sanzhi Dist, New Taipei City 25245, Taiwan. ${ }^{3}$ Department of Ophthalmology, Mackay Memorial Hospital, No. 92, Sec. 2, Chung Shan North Road, Taipei 10449, Taiwan. ${ }^{4}$ Graduate Institute of Microbiology, College of Medicine, National Taiwan University, 7F, No. 1, Sec. 1, Jen-Ai Rd., Taipei 10617, Taiwan.

Received: 16 August 2021 Accepted: 28 January 2022

Published online: 22 February 2022

\section{References}

1. Tombran-Tink J, Chader GG, Johnson LV. PEDF: a pigment epitheliumderived factor with potent neuronal differentiative activity. Exp Eye Res. 1991;53:411-4.

2. Dawson DW, Volpert OV, Gillis P, Crawford SE, Xu H, Benedict W, et al. Pigment epithelium-derived factor: a potent inhibitor of angiogenesis. Science. 1999:285:245-8.

3. Holekamp NM, Bouck N, Volpert O. Pigment epithelium-derived factor is deficient in the vitreous of patients with choroidal neovascularization due to age-related macular degeneration. Am J Ophthalmol. 2002;134:220-7.

4. Mirochnik Y, Aurora A, Schulze-Hoepfner FT, Deabes A, Shifrin V, Beckmann $\mathrm{R}$, et al. Short pigment epithelial-derived factor-derived peptide inhibits angiogenesis and tumor growth. Clin Cancer Res. 2009;15:1655-63.

5. Craword SE, Fitchev P, Veliceasa D, Volpert OV. The many facets of PEDF in drug discovery and disease: a diamond in the rough or split personality disorder? Expert Opin Drug Discov. 2013:8:769-92.

6. Filleur S, Volz K, Nelius T, Mirochnik Y, Huang H, Zaichuk TA, et al. Two functional epitopes of pigment epithelial-derived factor block angiogenesis and induce differentiation in prostate cancer. Cancer Res. 2005:65:5144-52.

7. Alberdi E, Aymerich MS, Becerra SP. Binding of pigment epitheliumderived factor (PEDF) to retinoblastoma cells and cerebellar granule neurons. Evidence for a PEDF receptor. J Biol Chem. 1999;274:31605-12.

8. Eichmann A, Simons M. VEGF signaling inside vascular endothelial cells and beyond. Curr Opin Cell Biol. 2012;24:188-93.

9. Huang $\mathrm{H}$. Pericyte-endothelial interactions in the retinal microvasculature. Int J Mol Sci. 2020;21:7413.

10. Mettu PS, Allingham MJ, Cousins SW. Incomplete response to anti-VEGF therapy in neovascular AMD: exploring disease mechanisms and therapeutic opportunities. Prog Retin Eye Res. 2021;82:100906.

11. Seki R, Yamagishi S, Matsui T, Yoshida T, Torimura T, Ueno T, et al. Pigment epithelium-derived factor (PEDF) inhibits survival and proliferation of VEGF-exposed multiple myeloma cells through its anti-oxidative properties. Biochem Biophys Res Commun. 2013;431:693-7.

12. Fogli S, Del Re M, Rofi E, Posarelli C, Figus M, Danesi R. Clinical pharmacology of intravitreal anti-VEGF drugs. Eye (Lond). 2018;32:1010-20.

13. Ho TC, Chen SL, Yang YC, Chen CY, Feng FP, Hsieh JW, et al. 15-deoxyDelta(12,14)-prostaglandin J2 induces vascular endothelial cell apoptosis through the sequential activation of MAPKS and p53. J Biol Chem. 2008;283:30273-88

14. Kenyon BM, Voest EE, Chen CC, Flynn E, Folkman J, D'Amato RJ. A model of angiogenesis in the mouse cornea. Invest Ophthalmol Vis Sci. 1996;37:1625-32.

15. Matsui T, Higashimoto $Y$, Yamagishi S. Laminin receptor mediates anti-inflammatory and anti-thrombogenic effects of pigment epithelium-derived factor in myeloma cells. Biochem Biophys Res Commun. 2014;443:847-51

16. Zhang H, Wei T, Jiang $X$, Li Z, Cui H, Pan J, et al. PEDF and 34-mer inhibit angiogenesis in the heart by inducing tip cells apoptosis via up-regulating PPAR-gamma to increase surface FasL. Apoptosis. 2016;21:60-8.

17. Melchionna M, Styan KE, Marchesan S. The unexpected advantages of using D-amino acids for peptide self- assembly into nanostructured hydrogels for medicine. Curr Top Med Chem. 2016;16:2009-18.

18. Garcia-Bates TM, Bernstein SH, Phipps RP. Peroxisome proliferatoractivated receptor gamma overexpression suppresses growth and induces apoptosis in human multiple myeloma cells. Clin Cancer Res. 2008;14:6414-25.

19. Ho TC, Chen SL, Yang YC, Liao CL, Cheng HC, Tsao YP. PEDF induces p53-mediated apoptosis through PPAR gamma signaling in human umbilical vein endothelial cells. Cardiovasc Res. 2007;76:213-23.

20. Hicks LD, Minnick MF. Human vascular endothelial cells express epithelial growth factor in response to infection by Bartonella bacilliformis. PLoS Negl Trop Dis. 2020;14:e0008236.

21. Mori K, Duh E, Gehlbach P, Ando A, Takahashi K, Pearlman J, et al. Pigment epithelium-derived factor inhibits retinal and choroidal neovascularization. J Cell Physiol. 2001;188:253-63.

22. Park K, Jin J, Hu Y, Zhou K, Ma JX. Overexpression of pigment epitheliumderived factor inhibits retinal inflammation and neovascularization. Am J Pathol. 2011;178:688-98.

23. Sagheer U, Gong J, Chung C. Pigment epithelium-derived factor (PEDF) is a determinant of stem cell fate: lessons from an ultra-rare disease. J Dev Biol. 2015:3:112-28.

24. Konson A, Pradeep S, D'Acunto CW, Seger R. Pigment epitheliumderived factor and its Phosphomimetic mutant induce JNK-dependent apoptosis and P38-mediated migration arrest. Cell Physiol Biochem. 2018:49:512-29.

25. Zaichuk TA, Shroff EH, Emmanuel R, Filleur S, Nelius T, Volpert OV. Nuclear factor of activated $T$ cells balances angiogenesis activation and inhibition. J Exp Med. 2004;199:1513-22

26. Bernard A, Gao-Li J, Franco CA, Bouceba T, Huet A, Li Z. Laminin receptor involvement in the anti-angiogenic activity of pigment epitheliumderived factor. J Biol Chem. 2009;284:10480-90.

\section{Publisher's Note}

Springer Nature remains neutral with regard to jurisdictional claims in published maps and institutional affiliations.

Ready to submit your research? Choose BMC and benefit from

- fast, convenient online submission

- thorough peer review by experienced researchers in your field

- rapid publication on acceptance

- support for research data, including large and complex data types

- gold Open Access which fosters wider collaboration and increased citations

- maximum visibility for your research: over 100M website views per year

At BMC, research is always in progress.

Learn more biomedcentral.com/submissions 